\title{
Обоснование режимов градиентного воздействия постоянного магнитного поля на листья табака в процессе их переработки
}

\author{
Виневский Евгений Иванович \\ ФГБНУ «Всероссийский научно-исследовательский \\ институт табака, махорки и табачных изделий» \\ Адрес: 350072, г. Краснодар, ул. Московская, д. 42 \\ E-mail:vinevski@mail.ru
}

\author{
Чернов Александр Владимирович \\ ФГБНУ «Всероссийский научно-исследовательский \\ институт табака, махорки и табачных изделий» \\ Адрес: 350072, г. Краснодар, ул. Московская, д. 42 \\ E-mail:ChernovAlexander909@yandex.ru
}

\begin{abstract}
Изучалась возможность применения градиентного воздействия постоянного магнитного поля на растительное сырье, так как существуют гипотезы, что вода в нем при его обработке приобретает биологическую активность. Однако исследования по обоснованию его режимов, влияющих на изменение скорости удаления влаги из растительного сырья в процессе его переработки, не проводились. Целью исследований являлось обоснование режимов градиентного воздействия постоянного магнитного поля на листья табака, влияющих на процесс их сушки. Разработана методика проведения исследований и лабораторная установка по изучению влияния режимов градиентного воздействия постоянного магнитного поля на изменение относительной массы листьев табака в процессе сушки. Выдвинута рабочая гипотеза, что в зависимости от частоты и продолжительности градиентного воздействия постоянного магнитного поля скорость удаления влаги из табачных листьев может снижаться или увеличиваться. Установлено, что градиентное воздействие постоянного магнитного поля на среднюю жилку табачных листьев при высоте расположения магнитов $\mathrm{H}=65$ мм оказывает разностороннее воздействие на процесс сушки. При частоте воздействия 0,178 Гц и продолжительности обработки 11,2 сек процесс сушки затормаживается, а при частоте воздействия 0,178 Гц и продолжительности обработки 44,8 сек процесс сушки листьев ускоряется. При высоте расположения магнитов $\mathrm{H}=25$ мм наблюдалась тенденция ускорения процесс сушки на 28,8\% (частота воздействия 0,357 Гц; продолжительность обработки 112 сек). Дисперсионный анализ результатов экспериментальных исследований позволил установить, что продолжительность эффекта от градиентного воздействия повышается как с увеличением его частоты, так и продолжительности. Максимальный эффект обработки получен при градиентном воздействии постоянного магнитного поля на среднюю жилку табачного листа с частотой 0,357 Гц и продолжительности обработки 112 сек.
\end{abstract}

Ключевые слова: режимы, градиентное воздействие, листья табака, процесс, частота воздействия, магнитное поле, продолжительность

\section{Введение}

В настоящее время при производстве табачного сырья одной из самых актуальных задач является решение проблемы снижения себестоимости его производства путем уменьшения энергоемкости сушки листьев табака.

До настоящего времени наиболее распространенным является конвективный способ сушки растительного сырья, при котором через него про- дувается воздух, нагретый до определенных температур (Волончук, Сапожников, \& Шорников, 2011).

Для решения проблемы снижения энергоемкости процесса сушки листьев табака ФГБНУ ВНИИТТИ проведен мониторинг методов физического воздействия на сельскохозяйственное сырье (Виневский, 2017). Установлено следующее (Григорьев, 2010; Лягина, 2010; Очиров, 2011; Худоногов, 2009):

- технологии, основанные на конвекционных механизмах обезвоживания, не обеспечивают 
качества получаемой продукции и характеризуются большой энергоемкостью процесса;

- современные и обеспечивающие высокое качество конечного продукта технологии сушки должны опираться на иные физические методы обезвоживания, на физические процессы, ход которых не так сильно связан с изменяющимися в процессе сушки собственными свойствами продуктов.

Анализ современных технологий сушки растительного сырья показал, что для растительного сырья с высоким исходным уровнем влажности процессы конвективной и ИК- или СВЧ- сушки объединяются в единую технологию:

- во влажном растительном сырье, при достаточно больших значениях параметров тепло - и массопроводности, конвективная сушка имеет преимущества в силу существенно более высокого КПД получения энергии;

- по мере уменьшения в процессе обезвоживания растительного сырья параметров тепло- и массопроводности и снижения эффективности конвекционной сушки менее энергоемкой становится инфракрасная и микроволновая суш$\mathrm{Ka}^{1,2}$.

Однако в последнее время наблюдается развитие других направлений использования магнитных полей при обработке сельскохозяйственного сырья. Одним из них является воздействие электромагнитного поля низких частот (ЭМП НЧ), которые имеют своей целью стимуляцию жизненных сил растений. В работе М.Г. Барышева, Г.И. Касьянова было показано, что воздействие электромагнитного поля крайне низких частот, имеющего определенные параметры, обладает свойством подавлять развитие грибковых микроорганизмов и бактерий (Барышев \& Касьянов, 2002). Аналогичные результаты получены в работе Р.С. Решетовой, М.Г. Барышева (Решетова \& Барышев, 2002).

Аналогичные исследования проводились в табачной отрасли. Кандидатом наук Плотниковой Т.В. проводились поисковые исследования по изучению возможности применения электромагнитного полями крайне низкой частоты (ЭМП КНЧ) при сушке листьев табака (Плотникова, Виневский, Грачев, \& Егоров, 2019). Установлено, что лучшие результаты получены при обработке частотой 30 Гц. На третьи сутки количество воды, испарившееся с обработанных листьев, было больше на 13,8\% чем на контроле, на 17 сутки на 48,4\%. Обработки частотой 27 Гц не существенно повлияли на скорость сушки сырья, так на третьи сутки данные превышали контроль на 8,1\%, на 17 сутки на 11,3\%.

В последние годы получили развитие исследования по изучению возможности применения градиентного воздействия постоянного (так называемого градиентного) магнитного поля (ГрМП) на растительное сырье, так как получают развитие научные гипотезы, что вода при ее обработке приобретает биологическую активность (Никулин, 1999; Новицкий \& Новицкая, 2016). Воздействие магнитного поля оказывает стимулирующее влияние, так как магнитоанизотропные молекулы ориентируются в пространстве и концентрируются в зоне воздействия магнитного поля, что оказывает стимулирующее влияние на скорость протекающих химических реакций (Батыгин, Говорун, \& Данилов, 1975; Данилов, 1987).

Во ВНИИТТИ проведены комплексные исследования по обоснованию процессов послеуборочной обработки табака. Изучено влияние магнитной обработки на качество табачного сырья (Антоненко, Ткаченко, \& Ветер, 2002). Установлено, что при обработке неферментированного табачного сырья в градиентном магнитном поле происходит снижение способности табака поглощать кислород из воздуха. Кроме того, установлено снижение никотина на 8-10\%.

Исследовано влияние магнитного поля на равновесную влажность табачного сырья (Ткаченко, 2003). Выявлено, что при этом снижается его равновесная влажность, что повышает стойкость табачного сырья к плесневению. По результатам проведенных исследований получен патент РФ на изобретение № 2232535 «Способ подготовки табака к ферментации». ${ }^{3}$

Исследовано влияние обработки магнитным полем на продолжительность процесса томления листьев табака различных сортов и их зрелости (Монастырева, Дьячкин, \& Антоненко, 2004). Выявлено, что продолжительность томления сокращается от 26 до 50\% в сравнении с контролем.

Григорьев, И. В., \& Рудобашта, С. П. (2010). РФ Патент № 2393397. Способ импульсной инфракрасной сушки термолабильных материалов.

2 Любайкин, С. Н., \& Рыбалко, Л. А. (2003). РФ Патент № 2216257. Способ сушки продуктов растительного происхождения.

3 Дьячкин, И. И., Ткаченко, А. М., Антоненко, И. И., Ветер, И. И., \& Лысенко, А. Е. (2004). РФ Патент № 2232535. Способ подготовки табака к ферментации. 
Изучалось влияние обработки табачного сырья физическими методами воздействия на технологические свойства резаного табака (Ткаченко, Дьячкин, \& Антоненко, 2004). Установлено, что резаный табак, обработанный ГрМП, обладает меньшей измельчаемостью и пылеобразованием по сравнению с необработанным. Выявлено, что у табачного сырья обработка ГрМП приводит к увеличению заполняющей способности резаного табака, которая в значительной степени определяется структурой ткани табачных листьев.

Проводились исследования по изучению воздействие градиентного магнитного поля на способность табачного сырья к поглощению кислорода (Монастырева \& Антоненко, 2008). Установлено, что обработка табачного сырья градиентным магнитным полем приводит к частичной инактивации фермента и снижению полифенолоксидазной активности.

Изучена возможность использования нового нетрадиционного способа обработки табачного сырья для увеличения его сорбционной способности (Антоненко, Дьячкин, Лещенко, \& Шкидюк, 2008). Установлено, что обработка градиентным магнитным полем оказывает положительное влияние на формирование основных потребительских свойств сигарет. Обработка табачного сырья омагниченным соусом повышает скорость поглощения соуса за счет активации молекул жидкости, позволяет улучшить курительные, технологические и актерицидные свойства сигарет. По результатам исследований получен патент РФ на изобретение № 2336000 «Способ обработки табачного сырья» ${ }^{\text {. }}$

Исследовалось влияние воздействия градиентного магнитного поля на химический состав табачного дыма курительных изделий (Антоненко, Лыгина, Герасина, \& Шкидюк, 2009). Показано, что интенсификация биохимических процессов в табаке приводит к снижению уровня токсичных компонентов табачного дыма. Воздействие градиентного магнитного поля позволяет снизить уровень токсичности табачного дыма при обработке пачек сигарет без нарушения целостности упаковки.

Для выбора физического метода воздействия на табак изучили влияние воздействия лазера и постоянного магнитного поля на скорость сушки листьев в искусственных условиях (Монастырева, 2012). Установлено, что обработка постоянным магнитным полем в среднем на 7,5\% быстрее удаляет вла- гу при сушке табака по сравнению с лазером. Оба физических метода воздействия снижают величину кислородного показателя от 16,47\% до 18,82\% у табака сортотипа Остролист и от 15,79 до 23,15 у табака сортотипа Трапезонд. Однако метод обработки лазерным излучением по всем полученным данным уступает постоянному магнитному полю, а также требует использования электроэнергии, специального помещения, разработки и изготовления специального аппаратурного оформления применительно к табачному производству. Метод обработки постоянным магнитным полем не требует использования электроэнергии.

Исследовано влияние воздействия ПМП на скорость сушки табака в искусственных условиях (Монастырева, 2012). Установлено, что скорость удаления влаги у табака, обработанного ПМП, существенно выше по сравнению с табаком, не прошедшим обработку. У опытной партии влагосодержание снижается на 0,092 кг/кг в час, а у контрольных - на 0,031 кг/кг в час. Таким образом, обработка свежеубранных листьев табака ПМП приводит к интенсификации процесса искусственной сушки за счет сокращения ее продолжительности до $30 \%$.

Исследовано влияния обработки постоянным магнитным полем (ПМП) на продолжительность ферментации табачного сырья (Монастырева, 2012). Установлено, что продолжительность процесса ферментации табачного сырья, обработанного ПМП, уменьшается от 33 до 50\%.

Однако исследования по обоснованию режимов градиентного воздействия постоянного магнитного поля на листья табака, влияющих на изменение скорости удаления из них влаги в процессе их переработки, не проводились.

Целью исследований являлось обоснование режимов градиентного воздействия постоянного магнитного поля на листья табака, влияющих на процесс их сушки.

\section{Материалы и методы исследований}

Разработана методика проведения исследований по изучению влияния режимов градиентного воздействия постоянного магнитного поля на изменение относительной массы листьев табака в процессе сушки.

\footnotetext{
4 Лысенко, А. Е., Дьячкин, И. И., Ветер, И. И., Лещенко, И. И., Антоненко, И. И., \& Ковалева, Я. В. (2008). РФ Патент № 2336000.
} Способ обработки табачного сырья (обработка соуса градиентным магнитным полем). 
На Рисунке 1 представлена лабораторная установка для изучения процессов градиентного воздействия постоянного магнитного поля на листья табака. Она состоит их транспортера 1 , над которым на высоте Н расположен экран 2 с магнитами 3 с шагом $t$ между собой.

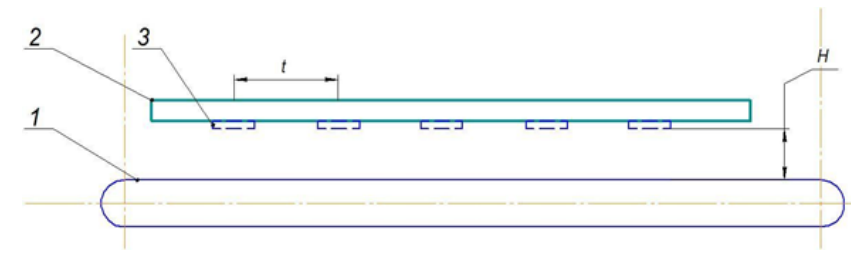

1 - транспортер; 2 - экран; 3 - магнит

Рисунок 1. Схема лабораторной установки для изучения процессов градиентного воздействия постоянного магнитного поля на листья табака

В Таблице 1 представлена техническая характеристика лабораторной установки для изучения процессов градиентного воздействия постоянного магнитного поля на листья табака.

Таблица 1

Техническая характеристика лабораторной установки для изучения процессов градиентного воздействия постоянного магнитного поля на листья табака

\begin{tabular}{lcccccc}
\hline \multicolumn{1}{c}{ Параметры } & \multicolumn{5}{c}{ Значения параметров } \\
\hline $\begin{array}{l}\text { Расстояние } \\
\text { между маг- }\end{array}$ & 0,09 & 0,09 & 0,09 & 0,18 & 0,18 & 0,18 \\
нитами, м & & & & & & \\
$\begin{array}{l}\text { Сила сцепле- } \\
\text { ния магнита, кг: }\end{array}$ & 2,5 & 2,5 & 2,5 & 2,5 & 2,5 & 2,5 \\
$\begin{array}{l}\text { Продолжитель- } \\
\text { ность прохожде- } \\
\text { ния между } \\
\text { двумя магни- } \\
\text { тами, сек }\end{array}$ & 2,8 & 1,73 & 1,12 & 5,6 & 5,6 & 5,6 \\
\hline
\end{tabular}

Частоту градиентного воздействия постоянного магнитного поля рассчитывали по формуле

$v=1 / \mathrm{T}$

где Т - продолжительность прохождения между двумя магнитами, сек

В Таблице 2 представлены расчетные значения параметров лабораторной установки для изучения процессов градиентного воздействия постоянного магнитного поля на листья табака.
Таблица 2

Расчетные значения параметров лабораторной установки для изучения процессов градиентного воздействия постоянного магнитного поля на листья табака

\begin{tabular}{|c|c|c|c|c|c|c|}
\hline Параметры & \multicolumn{6}{|c|}{ Значения параметров } \\
\hline \multicolumn{7}{|l|}{ Частота гра- } \\
\hline \multicolumn{7}{|l|}{ диентно- } \\
\hline \multicolumn{7}{|l|}{ го воздействия } \\
\hline \multicolumn{7}{|l|}{ постоянно- } \\
\hline \multicolumn{7}{|l|}{ го магнитного } \\
\hline поля, Герц & 0,357 & 0,578 & 0,893 & 0,179 & 0,179 & 0,179 \\
\hline \multicolumn{7}{|l|}{ Продолжитель- } \\
\hline \multirow{2}{*}{\multicolumn{7}{|c|}{$\begin{array}{l}\text { ности движе- } \\
\text { ния листа под }\end{array}$}} \\
\hline & & & & & & \\
\hline экраном, сек & 14 & 8,65 & 5,6 & 11,2 & 11,2 & 11,2 \\
\hline \multicolumn{2}{|l|}{$\begin{array}{l}\text { Количество об- } \\
\text { работок, шт. }\end{array}$} & \multicolumn{5}{|c|}{$\begin{array}{l}\text { Общая продолжитель- } \\
\text { ность обработки, сек }\end{array}$} \\
\hline 1 & 14 & 8,65 & 5,6 & 11,2 & 11,2 & 11,2 \\
\hline 4 & 56 & 34,6 & 22,4 & 44,8 & 44,8 & 44,8 \\
\hline 8 & 112 & 69,2 & 44,8 & 89,6 & 89,6 & 89,6 \\
\hline Скорость, м/с & 0,032 & 0,052 & 0,080 & 0,032 & 0,032 & 0,032 \\
\hline
\end{tabular}

\section{Результаты и их обсуждение}

Проведены экспериментальные исследования по изучению влияния режимов градиентного воздействия постоянного магнитного поля на изменение относительной массы листьев табака в процессе сушки. Предварительно была выдвинута гипотеза, что в зависимости от частоты и продолжительности градиентного воздействия постоянного магнитного поля скорость удаления влаги из табачных листьев может снижаться или увеличиваться.

Изучены следующие режимы градиентного воздействия постоянного магнитного поля на табачный лист (Рисунки 2, 5):

- высота расположения магнитов $\mathrm{H}=25 \mathrm{Mм} ; \mathrm{H}=$ $=65 \mathrm{MM}$;

- частота воздействия градиентного магнитного поля - 0,178 Гц; 0,357 Гц; 0,578 Гц; 0,893 Гц;

- продолжительность воздействия на табачный лист - от 5,6 сек до 112 сек.

Результаты исследований по изучению влияния режимов градиентного воздействия постоянного магнитного поля на продолжительность томления листьев табака представлены на Рисунках 4 и 6. 

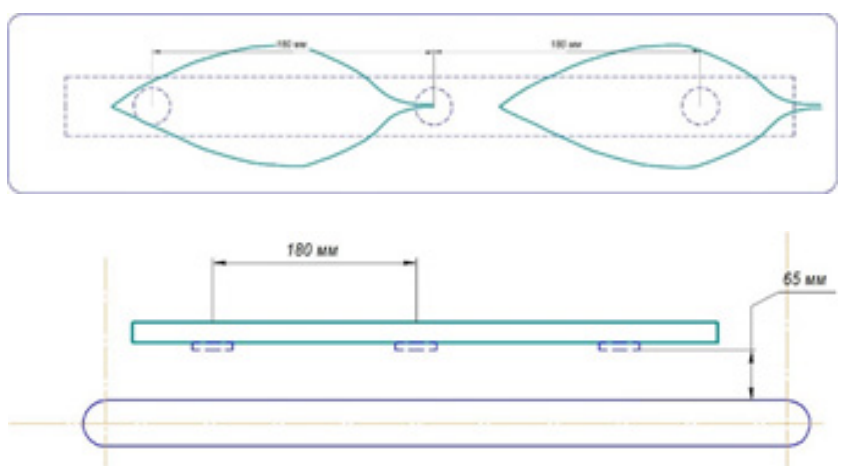

a
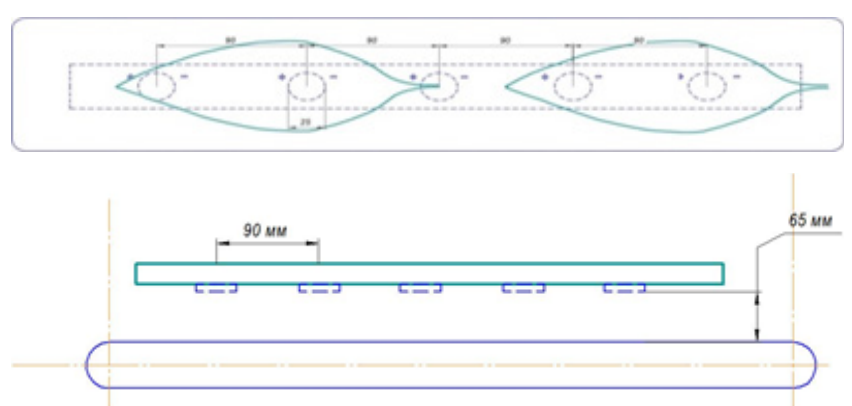

6

$\mathrm{a}-\mathrm{L}=180 \mathrm{Mm} ; \sigma-\mathrm{L}=90 \mathrm{MM}$

Рисунок 2. Схемы опытов градиентного воздействия постоянного магнитного поля на листья табака $(\mathrm{H}=65 \mathrm{Mm})$

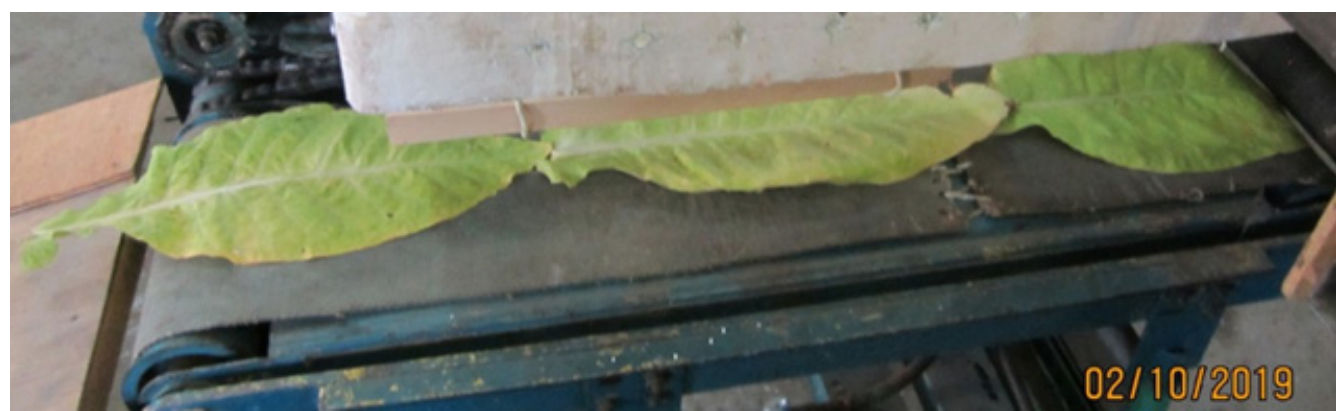

Рисунок 3. Фотография точечного градиентного воздействия постоянного магнитного поля на листья табака

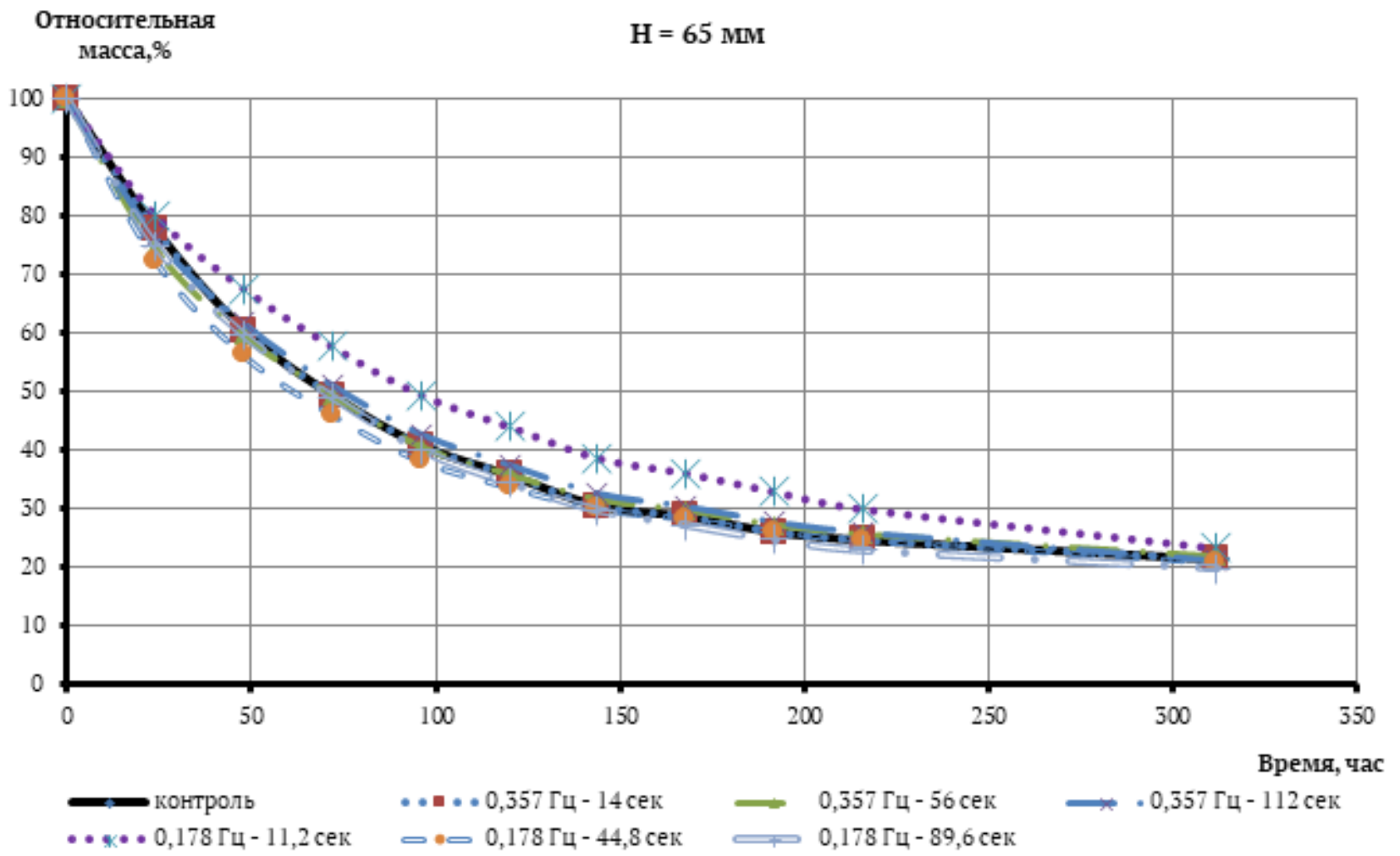

Рисунок 4. Влияние параметров и режимов градиентного воздействия постоянного магнитного поля на изменение относительной массы листьев табака в процессе сушки (H=65мм) 

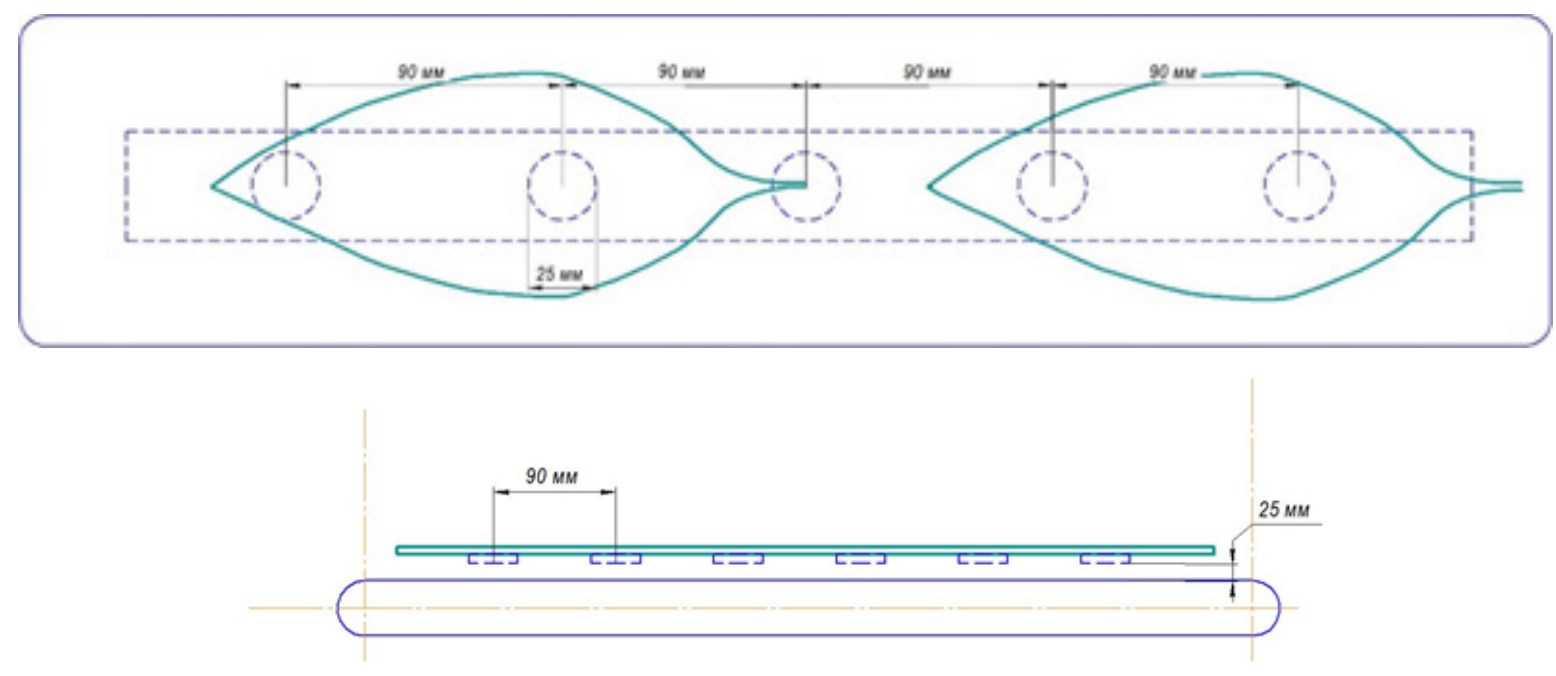

Рисунок 5. Схемы опытов градиентного воздействия постоянного магнитного поля на листья табака $(\mathrm{H}=25 \mathrm{Mm})$

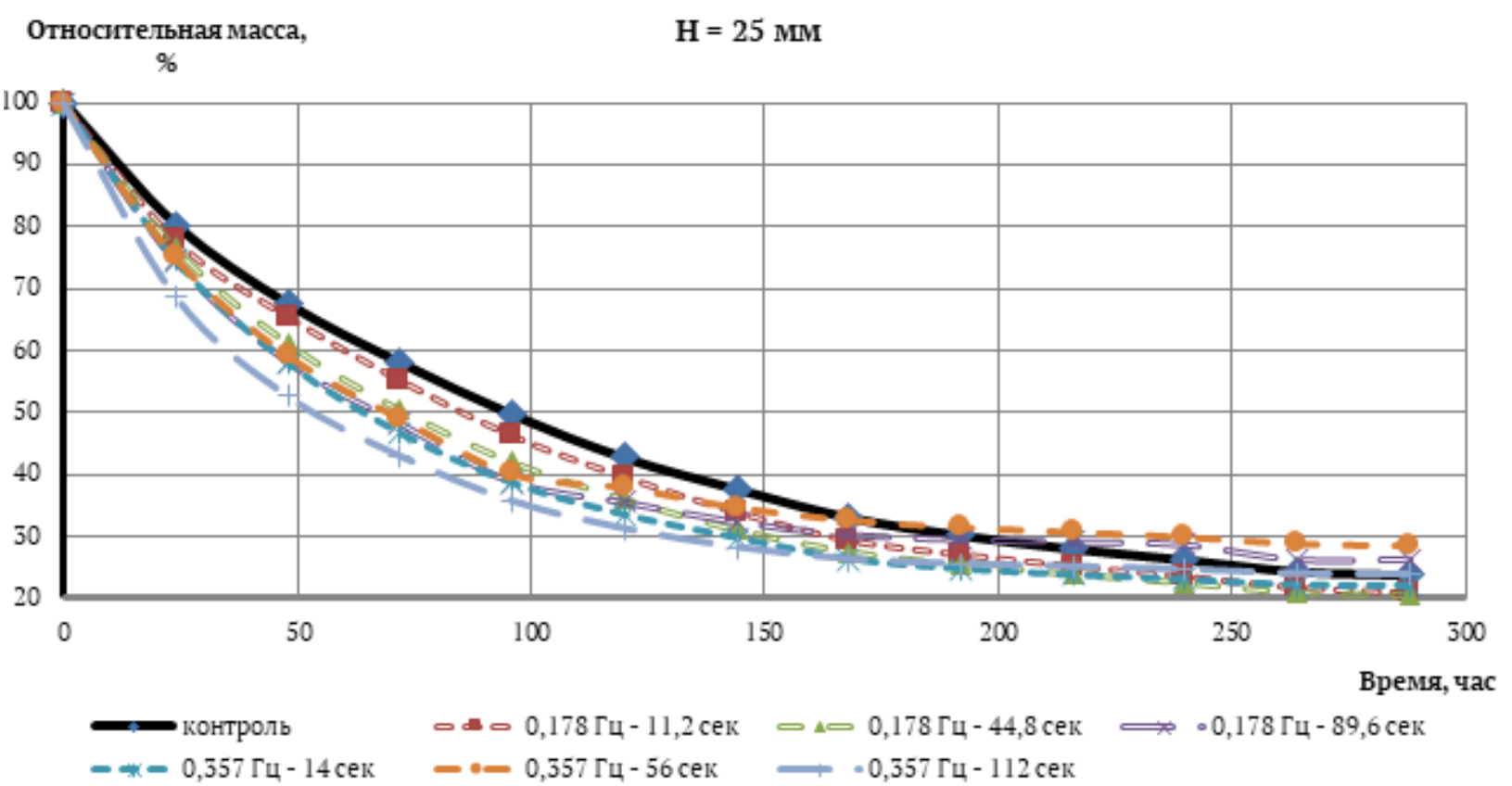

Рисунок 6. Влияние режимов градиентного воздействия постоянного магнитного поля на изменение относительной массы листьев табака в процессе сушки (Н=25мм)

Установлено следующее:

- градиентное воздействие постоянного магнитного поля на листья табака при высоте расположения магнитов $\mathrm{H}=65$ мм оказывает разностороннее воздействие на процесс сушки. Так, при частоте воздействия 0,178 Гц и продолжительности обработки 11,2 сек процесс сушки затормаживается на $11,4 \%$, а при частоте воздействия 0,178 Гц и продолжительности обработки 44,8 сек процесс сушки листьев ускоряется;
- при высоте расположения магнитов $\mathrm{H}=25$ мм градиентное воздействие постоянного магнитного поля на листья табака наблюдалась тенденция ускорения процесса их сушки на $28,8 \%$ (частота воздействия 0,357 Гц; продолжительность обработки 112 сек).

Для более углубленного анализа результатов исследований влияния режимов градиентного воздействия постоянного магнитного поля на изменение относительной массы листьев табака в процессе сушки был использован дисперсионный анализ. 
Определялось существует ли существенная разность между обработанными и контрольными образцами листьев.

Установлено следующее:

- эффект обработки от градиентного воздействия с частотой 0,357 Гц постоянного магнитного поля на листья табака продолжительностью 112 сек сохраняется в течение 192 часов; с увеличением продолжительности обработки с 56 сек до 112 сек существенная разность между опытными и контрольными листьями возрастает с 96 часов до 192 часов (прямо пропорциональная зависимость между продолжительностью обработки и эффектом обработки); как при градиентном воздействии с частотой 0,178 Гц в течение 89,6 сек, так и с частотой 0,357 Гц в течение 56 сек эффект обработки сохранялся 96 часов.

Таблица 3

Результаты дисперсионного анализа по определению влияния режимов градиентного воздействия постоянного магнитного поля на существенную разность относительных масс между обработанными и контрольными листьями

\begin{tabular}{|c|c|c|c|c|c|c|c|c|c|}
\hline \multirow{2}{*}{ 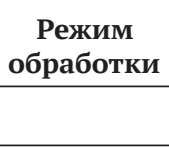 } & \multicolumn{9}{|c|}{ Время замера, час } \\
\hline & 24 & 48 & 72 & 96 & 120 & 144 & 168 & 192 & 216 \\
\hline $\begin{array}{c}\text { 0,178 Гц; } \\
89,6 \text { сек }\end{array}$ & 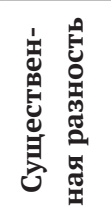 & 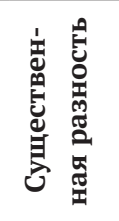 & 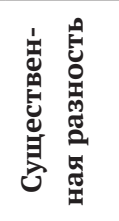 & 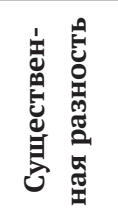 & 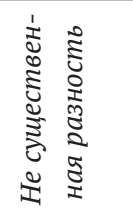 & 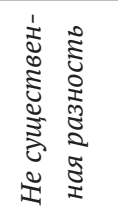 & 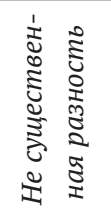 & 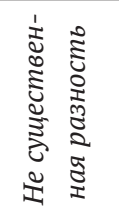 & 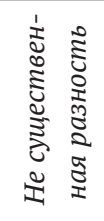 \\
\hline $\begin{array}{c}\text { 0,357 Гц; } \\
56 \text { сек }\end{array}$ & 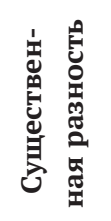 & 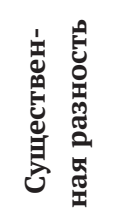 & 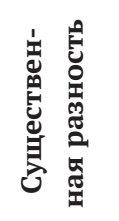 & 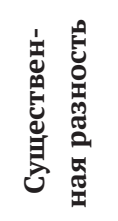 & 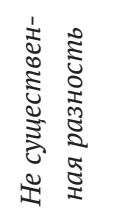 & 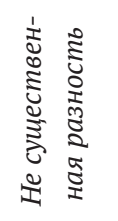 & 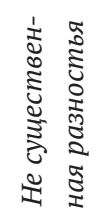 & 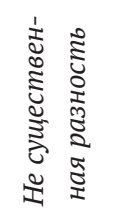 & 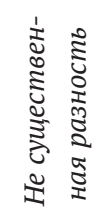 \\
\hline $\begin{array}{c}\text { 0,357 Гц; } \\
112 \text { сек }\end{array}$ & 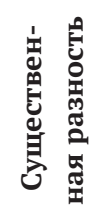 & 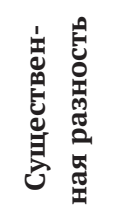 & 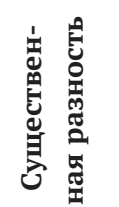 & 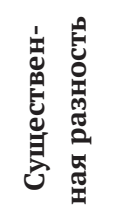 & 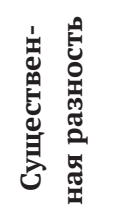 & 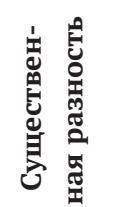 & 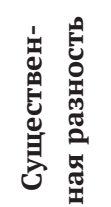 & 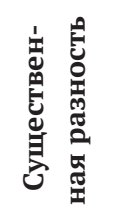 & 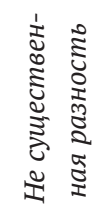 \\
\hline
\end{tabular}

\section{Выводы}

Определены режимы градиентного воздействия постоянного магнитного поля на листья табака, образующегося при перемещении листьев табака под полюсами магнитов, на изменение продолжительности их сушки. Установлено, что максимальный эффект обработки получен при градиентном воздействии постоянного магнитного поля на листья табака с частотой 0,357 Гц и продолжительности обработки 112 сек.

\section{Литература}

Антоненко, И. Г., Дьячкин, И. И., Лещенко, Т. Ф., \& Шкидюк, М. В. (2008). Влияние обработки магнитным полем табачного сырья на интенсифи- кацию процесса соусирования. Сборник научных трудов ВНИИТТИ, 177, 259-264.

Антоненко, И. Г., Лыгина, Л. В., Герасина, И. В., \& Шкидюк, М. В. (2009). Влияние магнитного поля на химический состав дыма сигарет. Сборник научных трудов ВНИИТТИ, 178, 81-84.

Антоненко, И. Г., Ткаченко, А. М., \& Ветер, И. И. (2002). Влияние магнитной обработки на качество табачного сырья. В Технологические аспекты комплексной переработки сельскохозяйственного сырья при производстве экологически безопасных пищевых продуктов общего и специального назначения: Труды научно-практической конференции (с. 37-38). Углич: Россельхозакадемия.

Барышев, М. Г., \& Касьянов, Г. И. (2002). Электромагнитная обработка сырья растительного и животного происхождения. Краснодар: КубГТу. 
Батыгин, Н. Ф., Говорун, Р. Д., \& Данилов, В. И. (1975). Метод предпосевной обработки клубней картофеля градиентным магнитным полем. Дубна: Сообщение ОИЯИ.

Виневский, Е. И. (2017). Мониторинг современных физических методов обработки сельскохозяйственного сырья. В Инновационные исследования и разработки для научного обеспечения производства и хранения экологически безопасной сельскохозяйственной и пищевой продукции: Сборник материалов II Международной научно-практической конференции (с. 284-289). Краснодар: ФГБНУ ВНИИТТИ.

Волончук, С. К., Сапожников, А. Н., \& Шорников, Л. П. (2011). Энергосберегающие технологии переработки растительного сырья. Ползуновский вестник, 2, 166-171. URL: http://elib.altstu.ru/journals/ Files/pv2011_02_1/pdf/166volonchuk.pdf (дата обращения: 13.02.2021).

Григорьев, И. В. (2010). Импульсная инфракрасная сушка семян овощных культур, нетрадиционных и редких растений (Автореферат диссертации ... кандидата техн. наук). М.: ФГОУ ВПО МГАУ.

Данилов, В. И. (1987). Магнитное поле и сельское хозяйство: Материалы совещания. Дубна: ОИЯИ.

Лягина, Л. А. (2010). Повышение эффективности сушки продуктов растительного происхождения за счет инфракрасно-конвективного воздействия (Автореферат диссертации кандидата техн. наук). Саратов: ФГОУ ВПО «Саратовский государственный аграрный университет им. Н. И. Вавилова».

Монастырева, А. М. (2012). Влияние обработки градиентным магнитным полем на продолжительность ферментации табачного сырья. Известия вузов. Пищевая технология, 2-3, 111-112.

Монастырева, А. М. (2012). Интенсификация процесса искусственной сушки табачных листьев под воздействием градиентного магнитного поля. Известия вузов. Пищевая технология, 2-3, 25-26.

Монастырева, А. М. (2012). Обоснование выбора физического метода воздействия на табак для интенсификации послеуборочной обработки табака. Политематический сетевой электронный журнал Кубанского государственного аграрного университета (Научный журнал КубГАУ), 5(79).

Монастырева, А. М., \& Антоненко, И. Г. (2008). Воздействие магнитного поля на изменение активности ферментов в процессе ферментации. Сборник научных трудов ВНИИТТИ, 177, 264-268.

Монастырева, А. М., Дьячкин, И. И., \& Антоненко, И. Г. (2004). Влияние обработки магнитным полем на продолжительность процесса томления табака. В Производство пищевых продуктов в соответствии с требованиями концепции здорового питания и другие вопросы: Материалы Всероссийской научно-практической конференции (с. 357-359). Волгоград: Гу ВНИТИММС и ППЖ РАСХН.

Никулин, М. А. (1999). О механизме биологического действия магнитных полей. В Материалы Международной научно-производственной конференции по магнитологии (с. 35-36). Витебск. Новицкий, Ю. И., Новицкая, Г. В. (2016). Действие постоянного магнитного поля на растения. М.: Наука.

Очиров, В. Д. (2011). Обоснование режимов ИК энергоподвода в технологии сушки корнеплодов моркови импульсными керамическими преобразователями излучения (Автореферат диссертации кандидата техн. наук). Иркутск: ФГОУ ВПО «Иркутская государственная сельскохозяйственная академия.

Плотникова, Т. В., Виневский, Е. И., Грачев, А. В., \& Егоров, Е. В. (2019). Результаты поисковых исследований по изучению влияния электромагнитного поля крайне низкой частоты (ЭМП КНЧ) на жизнедеятельность микромицетов и беспозвоночных организмов. В Инновационные исследования и разработки для научного обеспечения производства и хранения экологически безопасной сельскохозяйственной и пищевой продукции: Сборник материалов III Международной научно-практической конференции (Т. 1, с. 452-458). Краснодар: ФГБНУ ВНИИТТИ.

Решетова, Р. С., \& Барышев, М. Г. (2002). Применение электромагнитного поля в свеклосахарном производстве. Краснодар: КубГТУ.

Ткаченко, А. М. (2003). Влияние магнитного поля на равновесную влажность табачного сырья. В Научное обеспечение агропромышленного комплекса: Материалы 5-й региональной научно-практич. конференции молодых ученых (с. 169-170). Краснодар: ФГНУ ВНИИТТИ.

Ткаченко, А. М., Дьячкин, И. И., \& Антоненко, И. Г. (2004). Влияние обработки табачного сырья физическими методами воздействия на технологические свойства резаного табака. Научное обеспечение производства и промышленной переработки табака. Сборник научных трудов ФГНУ ВНИИТТИ, 176, 169-172.

Худоногов, И. А. (2009). Ресурсосберегающие методы управления ИК-энергоподводом в процессах производства оздоровительного чая (Автореферат диссертации кандидата техн. наук). Красноярск: ФГОУ ВПО «Красноярский государственный аграрный университет». 


\title{
Proving Regimens for Gradient Constant Magnetic Field Treatment of Tobacco leaves During their Processing
}

\author{
Evgeny I. Vinevskii \\ All-Russian Research Institute of tobacco, makhorka and tobacco products \\ 42, Moskovskaya str., Krasnodar, 350072, Russian Federaton \\ E-mail:vinevski@mail.ru \\ Alexander V. Chernov \\ All-Russian Research Institute of tobacco, makhorka and tobacco products \\ 42, Moskovskaya str., Krasnodar, 350072, Russian Federaton \\ E-mail: ChernovAlexander909@yandex.ru
}

\begin{abstract}
Possibility of utilizing gradient constant magnetic field to plant material has been studied. There are theories that water after such treatment obtains biological activity. There is no researches on proving regimens that affect changing rate of water removing from plant material during its processing. Aim of the research was proving regimens for gradient constant magnetic field treatment of tobacco leaves during their processing and affecting the curing process. Method for carrying research and laboratory equipment for studying effect of different regimens of constant magnetic field on changing leaf mass during the curing process were elaborated. Hypothesis was offered that depending on frequency and time of constant gradient magnetic field treatment rate of water removing from tobacco leaves can increase or decrease. It is discovered that gradient treatment by constant magnetic field of midrib when height of magnets positioning is $65 \mathrm{~mm}$ affects on curing process in different ways. When frequency was $0.178 \mathrm{~Hz}$ and time of treatment 11.2 seconds curing process rate reduces and when time of treatment is 44.8 seconds curing process rate accelerates. When height of magnets positioning was $25 \mathrm{~mm}$ curing process accelerates by $28.8 \%$ (Frequency $0.357 \mathrm{~Hz}$; time of treatment 112 seconds). Dispersion analysis of research data discovered that duration of the magnetic field effect increases after increasing frequency and time of treatment. Maximum effect was noticed when treatment of tobacco midrib was carried with frequency $0.357 \mathrm{~Hz}$ and time of treatment 112 seconds.
\end{abstract}

Keywords: Regimens, gradient treatment, tobacco leaves, process, frequency of treatment, magnetic field, duration

\section{References}

Antonenko, I. G., D’yachkin, I. I., Leshchenko, T. F., \& Shkidyuk, M. V. (2008). Vliyanie obrabotki magnitnym polem tabachnogo syr'ya na intensifikatsiyu protsessa sousirovaniya [Influence of the processing of raw tobacco with a magnetic field on the intensification of the sauce process]. Sbornik nauchnykh trudov VNIITTI [Collection of scientific works of the All-russian research institute of tobacco, machorka and tobacco products], 177, 259-264.

Antonenko, I. G., Lygina, L. V., Gerasina, I. V., \& Shkidyuk, M. V. (2009). Vliyanie magnitnogo polya na khimicheskii sostav dyma sigaret [Influence of magnetic field on the chemical composition of cigarette smoke]. Sbornik nauchnykh trudov VNIITTI [Collection of scientific works of the Allrussian research institute of tobacco, machorka and tobacco products], 178, 81-84.

Antonenko, I. G., Tkachenko, A. M., Veter, I. I. (2002). Vliyanie magnitnoi obrabotki na kachestvo tabach- nogo syr'ya [Influence of magnetic processing on the quality of raw tobacco]. In Tekhnologicheskie aspekty kompleksnoi pererabotki sel'skokhozyaistvennogo syr'ya pri proizvodstve ekologicheski bezopasnykh pishchevykh produktov obshchego i spetsial'nogo naznacheniya: Trudy nauchno-prakticheskoi konferentsii [Technological aspects of complex processing of agricultural raw materials in the production of environmentally friendly food products for general and special purposes: Proceedings of the scientific and practical conference] (pp. 37-38). Uglich: Rossel'khozakademiya.

Baryshev, M. G., \& Kas'yanov, G. I. (2002). Elektromagnitnaya obrabotka syr'ya rastitel'nogo $i$ zhivotnogo proiskhozhdeniya [Electromagnetic processing of raw materials of plant and animal origin]. Krasnodar: KubGTU.

Batygin, N. F., Govorun, R. D., \& Danilov, V. I. (1975). Metod predposevnoi obrabotki klubnei kartofelya gradientnym magnitnym polem [Method of pre-sowing treatment of potato tubers with a gradient magnetic field]. Dubna: Soobshchenie OIYaI. 
Vinevskii, E. I. (2017). Monitoring sovremennykh fizicheskikh metodov obrabotki sel'skokhozyaistvennogo syr'ya [Monitoring of modern physical methods of processing agricultural raw materials]. In Innovatsionnye issledovaniya i razrabotki dlya nauchnogo obespecheniya proizvodstva i khraneniya ekologicheski bezopasnoi sel'skokhozyaistvennoi $i$ pishchevoi produktsii: Sbornik materialov II Mezhdunarodnoi nauchno-prakticheskoi konferentsii [Innovative research and development for scientific support of production and storage of ecologically safe agricultural and food products: Proceedings of materials of the 2nd International scientific and practical conference] (pp. 284-289). Krasnodar: FGBNU VNIITTI.

Volonchuk, S. K., Sapozhnikov, A. N., \& Shornikov, L. P. (2011). Energosberegayushchie tekhnologii pererabotki rastitel'nogo syr'ya [Energy-saving technologies for processing plant raw materials]. Polzunovskii vestnik [Polzunovsky Bulletin], 2, 166-171. URL: http://elib.altstu.ru/journals/ Files/pv2011_02_1/pdf/166volonchuk.pdf (дата обращения: 13.02.2021).

Grigor'ev, I. V. (2010). Impul'snaya infrakrasnaya sushka semyan ovoshchnykh kul'tur, netraditsionnykh i redkikh rastenii (Avtoreferat dissertatsii kandidata tekhn. nauk) [Impulse infrared drying of vegetable seeds, non-traditional and rare plants (Unpublished master's thesis)]. Moscow: FGOU VPO MGAU.

Danilov, V. I. (1987). Magnitnoe pole i sel'skoe khozyaistvo: Materialy soveshchaniya [Magnetic Field and Agriculture: Meeting Proceedings]. Dubna: OIYaI.

Lyagina, L. A. (2010). Povyshenie effektivnosti sushki produktov rastitel'nogo proiskhozhdeniya za schet infrakrasno-konvektivnogo vozdeistviya (Avtoreferat dissertatsii kandidata tekhn. nauk) [Increasing the efficiency of drying products of plant origin due to infrared-convective action (Unpublished master's thesis)]. Saratov: FGOU VPO «Saratovskii gosudarstvennyi agrarnyi universitet im. N. I. Vavilova».

Monastyreva, A. M. (2012). Vliyanie obrabotki gradientnym magnitnym polem na prodolzhitel'nost' fermentatsii tabachnogo syr'ya [Influence of treatment with a gradient magnetic field on the duration of fermentation of raw tobacco]. Izvestiya vuzov. Pishchevaya tekhnologiya [University news. Food technology], 2-3, 111-112.

Monastyreva, A. M. (2012). Intensifikatsiya protsessa iskusstvennoi sushki tabachnykh list'ev pod vozdeistviem gradientnogo magnitnogo polya [Intensification of the process of artificial drying of tobacco leaves under the influence of a gradient magnetic field]. Izvestiya vuzov. Pishchevaya tekhnologiya [University news. Food technology], 2-3, 25-26.
Monastyreva, A. M. (2012). Obosnovanie vybora fizicheskogo metoda vozdeistviya na tabak dlya intensifikatsii posleuborochnoi obrabotki tabaka [Substantiation of the choice of the physical method of exposure to tobacco for the intensification of post-harvest tobacco processing]. Politematicheskii setevoi elektronnyi zhurnal Kubanskogo gosudarstvennogo agrarnogo universiteta (Nauchnyi zhurnal KubGAU) [Polythematic network electronic journal of the Kuban State Agrarian University], 5(79). URL: http://ei.kubagro.ru/2012/05/pdf/30.pdf (accessed: 14.01.2021).

Monastyreva, A. M., \& Antonenko, I. G. (2008). Vozdeistvie magnitnogo polya na izmenenie aktivnosti fermentov $v$ protsesse fermentatsii [The effect of a magnetic field on the change in the activity of enzymes during fermentation]. Sbornik nauchnykh trudov VNIITTI [Collection of scientific works of the All-russian research institute of tobacco, machorka and tobacco products], 177, 264-268.

Monastyreva, A. M., D'yachkin, I. I., \& Antonenko, I. G. (2004). Vliyanie obrabotki magnitnym polem na prodolzhitel'nost' protsessa tomleniya tabaka [Influence of processing by a magnetic field on the duration of the tobacco languishing process]. In Proizvodstvo pishchevykh produktov $v$ sootvetstvii s trebovaniyami kontseptsii zdorovogo pitaniya $i$ drugie voprosy: Materialy Vserossiiskoi nauchno-prakticheskoi konferentsii [Food production in accordance with the requirements of the concept of healthy nutrition and other issues: Materials of the All-Russian Scientific and Practical Conference] (pp. 357-359). Volgograd: GU VNITIMMS i PPZh RASKhN.

Nikulin, M. A. (1999). O mekhanizme biologicheskogo deistviya magnitnykh polei [On the mechanism of the biological action of magnetic fields]. In Materialy Mezhdunarodnoi nauchno-proizvodstvennoi konferentsii po magnitologii [Materials of the International Scientific and Production Conference on Magnetology] (pp. 35-36). Vitebsk.

Novitskii, Yu. I., Novitskaya, G. V. (2016). Deistvie postoyannogo magnitnogo polya na rasteniya [The effect of a constant magnetic field on plants]. Moscow: Nauka.

Ochirov, V. D. (2011). Obosnovanie rezhimov IK - energopodvoda $v$ tekhnologii sushki korneplodov morkovi impul'snymi keramicheskimi preobrazovatelyami izlucheniya (Avtoreferat dissertatsii kandidata tekhn. nauk) [Substantiation of modes of IR - energy supply in the technology of drying carrots by pulsed ceramic radiation converters (Unpublished master's thesis)]. Irkutsk: FGOU VPO «Irkutskaya gosudarstvennaya sel'skokhozyaistvennaya akademiya. Plotnikova, T. V., Vinevskii, E. I., Grachev, A. V., \& Egorov, E. V. (2019). Rezul'taty poiskovykh issle- 
dovanii po izucheniyu vliyaniya elektromagnitnogo polya kraine nizkoi chastoty (EMP KNCh) na zhiznedeyatel'nost' mikromitsetov i bespozvonochnykh organizmov [Results of exploratory studies to study the effect of an extremely low frequency electromagnetic field on the vital activity of micromycetes and invertebrates]. In Innovatsionnye issledovaniya $i$ razrabotki dlya nauchnogo obespecheniya proizvodstva i khraneniya ekologicheski bezopasnoi sel'skokhozyaistvennoi i pishchevoi produktsii: Sbornik materialov III Mezhdunarodnoi nauchno-prakticheskoi konferentsii [Innovative research and development for scientific support of production and storage of ecologically safe agricultural and food products: Proceedings of materials of the 3rd International scientific and practical conference] (Vol. 1, pp. 452-458). Krasnodar: FGBNU VNIITTI.

Reshetova, R. S., \& Baryshev, M. G. (2002). Primenenie elektromagnitnogo polya $v$ sveklosakharnom proizvodstve [Application of an electromagnetic field in sugar beet production]. Krasnodar: KubGTU.

Tkachenko, A. M. (2003). Vliyanie magnitnogo polya na ravnovesnuyu vlazhnost' tabachnogo syr'ya [Influence of the magnetic field on the equilibrium moisture content of raw tobacco]. In Nauchnoe obespechenie agropromyshlennogo kompleksa: Materialy 5-i regional'noi nauchno-praktich. konferentsii molodykh uchenykh [Scientific support of the agro-industrial complex: Materials of the 5th regional scientific and practical. conferences of young scientists] (pp. 169-170). Krasnodar: FGNU VNIITTI.

Tkachenko, A. M., D’yachkin, I. I., \& Antonenko, I. G. (2004). Vliyanie obrabotki tabachnogo syr'ya fizicheskimi metodami vozdeistviya na tekhnologicheskie svoistva rezanogo tabaka. Nauchnoe obespechenie proizvodstva i promyshlennoi pererabotki tabaka [Influence of processing raw tobacco by physical methods of influence on the technological properties of cut tobacco. Scientific support for the production and industrial processing of tobacco]. Sbornik nauchnykh trudov FGNU VNIITTI [Collection of scientific works of the Allrussian research institute of tobacco, machorka and tobacco products], 176, 169-172.

Khudonogov, I. A. (2009). Resursosberegayushchie metody upravleniya IK-energopodvodom $v$ protsessakh proizvodstva ozdorovitel'nogo chaya (Avtoreferat dissertatsii kandidata tekhn. nauk) [Resource-saving methods for controlling the IR power supply in the production of health-improving tea (Unpublished master's thesis)]. Krasnoyarsk: FGOU VPO «Krasnoyarskii gosudarstvennyi agrarnyi universitet». 